\title{
Impact of supply chain integration and intelligent information systems in achieving supply chain innovation: A study of retail trading SMEs in Abu Dhabi, UAE
}

\author{
Anas Abudaqa ${ }^{a^{*}}$, Mohd Faiz Hilmia, Norziani Dahalan ${ }^{a}$ and Hasan AlMujaini ${ }^{a}$
}

\begin{tabular}{l}
${ }^{a}$ School of Distance Education, Univ \\
\hline C H R O N I C L E \\
\hline Article history: \\
Received April 15, 2020 \\
Received in revised format June \\
8,2020 \\
Accepted July 272020 \\
Available online \\
July 272020 \\
\hline Keywords: \\
Supply chain Innovation \\
Supply chain Integration \\
Supply chain orientation \\
Competition capability \\
Intelligent Information system \\
SMEs
\end{tabular}

\section{Introduction}

Small and Medium Enterprises (SMEs) in Abu Dhabi account for 98\% of all companies in this region (Rahim Sid Ahmed $\&$ Wiegert, 2019) and contribute about twenty-nine percent towards the gross domestic product (GDP). According to the same sources, the SMEs in Abu Dhabi create an average of 223,000 jobs every year. As per information published by Rahim Sid Ahmed and Wiegert (2019), the SMEs of Abu Dhabi are categorized into service, manufacturing, and trading segments. The trading segment generates an annual turnover of 50-250 million AED and employs a workforce of 6-250 persons. The manufacturing segment of SMEs generates an annual turnover of 50-250 million AED and employs a workforce of 10-250 persons. Finally, the service segment generates 20-200 million AED and employs a workforce of 6-200 persons. The retail trading segment is the most dominant SME segment in Abu Dhabi. It provides jobs to more than $90 \%$ of the work force population (Rahim Sid Ahmed \& Wiegert, 2019; SCAD, 2020). The retail trading SMEs in Abu Dhabi requires innovation in their supply chain, and this can be achieved by considering the supply chain integration, supply chain orientation, and competition capabilities along with the mediation of intelligent information systems as key contributors. The world is changing rapidly and this requires the constant upgradation of the supply chain system to enhance the innovative systems of the supply chain (Ho et al., 2016; Singhry, 2015).

\footnotetext{
* Corresponding author Tel.: +971507619161

E-mail address: aabudaqa1@gmail.com (A. Abudaqa)

(C) 2020 by the authors; licensee Growing Science. doi: $10.5267 /$ j.uscm.2020.7.009 


\section{Theorectical framework}

This exploratory study aims to achieve innovation in supply chain management for retail trading SMEs in Abu Dhabi by considering the importance of supply chain integration, supply chain orientation, and competitive capability along with the mediation role of intelligent information systems. Fig. 1 elaborates the theoretical link between these constructs as follows:

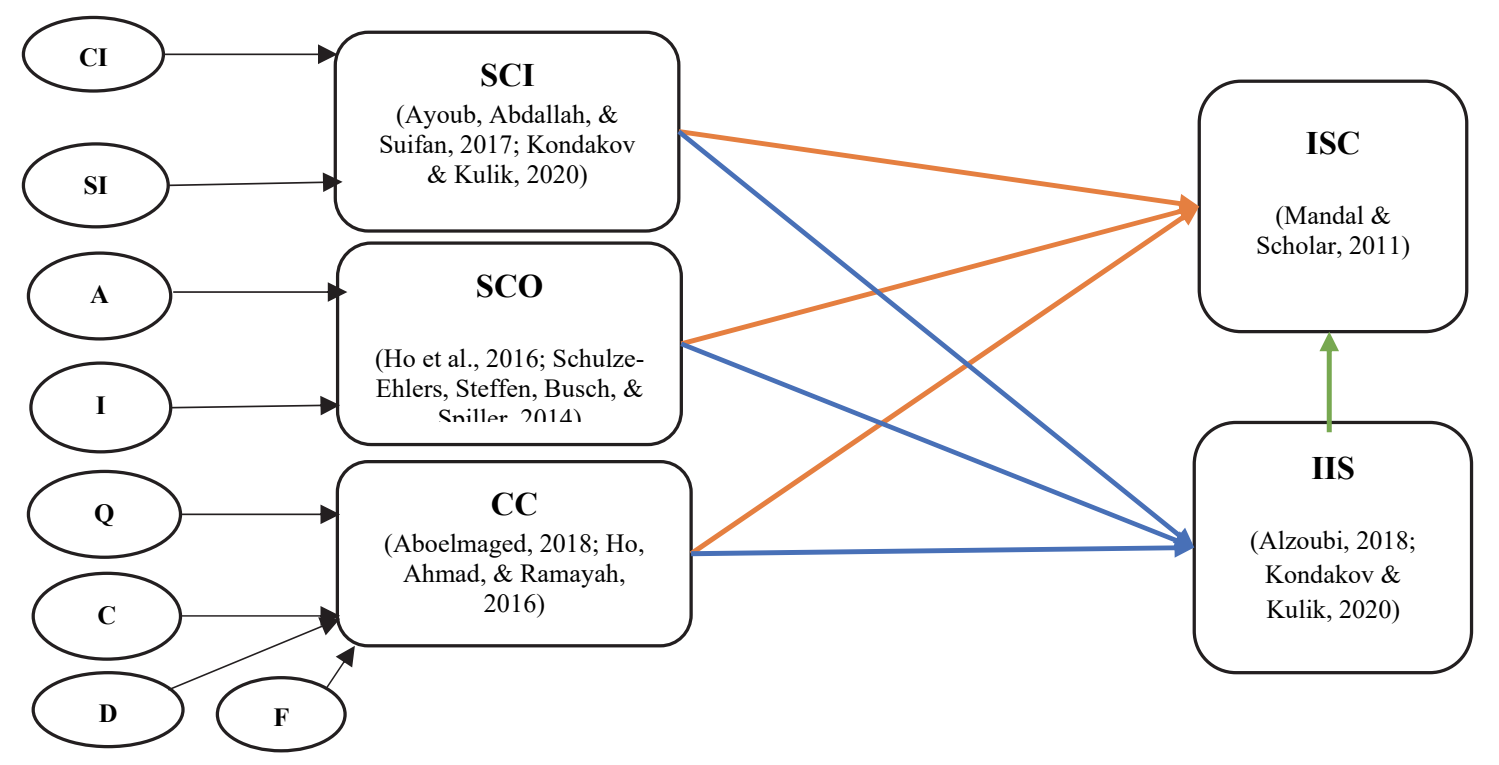

Where: $\mathrm{CI}=$ Customer Integration, $\mathrm{SI}=$ Supplier Integration, $\mathrm{SCI}=$ Supply chain Integration, $\mathrm{A}=\mathrm{Attitude}, \mathrm{I}=\mathrm{Intention}$, $\mathrm{SCO}=$ Supply Chain Orientation, $\mathrm{Q}=$ Quality, $\mathrm{C}=$ Cost, $\mathrm{D}=$ Delivery, $\mathrm{F}=$ Flexibility, $\mathrm{CC}=$ Competition capability, ISC $=$ Innovative Supply chain, IIS = Intelligent Information system.

Fig. 1. Theoretical Framework

The figure further elaborates the important dimensions of all these constructs, along with the references used for their measurement.

\subsection{Operational definition}

The definition of various constructs along with their working dimensions are summarized in Table 1, along with references from previous studies.

Table 1

Operational Definitions of Constructs

\begin{tabular}{|c|c|c|}
\hline Construct & Definition & Article References \\
\hline Supply chain integration & $\begin{array}{l}\text { "A process supporting the integration of all the relevant parties of the supply } \\
\text { chain, like the customer and supplier, with the motive of working effectively to } \\
\text { achieve the common goals, is considered supply chain integration." }\end{array}$ & $\begin{array}{l}\text { (Adebanjo, Teh, \& Ahmed, } \\
\text { 2018) }\end{array}$ \\
\hline Supply chain orientation & $\begin{array}{l}\text { "A strategic, systematic, attitudinal, intentional implication of the processes and } \\
\text { activities required to manage the supply chain flow are considered as supply chain } \\
\text { orientation." }\end{array}$ & (Jadhav, Orr, \& Malik, 2019) \\
\hline Competition capability & $\begin{array}{l}\text { "A firm's real performance as compared to the market competitors based on cost, } \\
\text { quality, delivery, and flexibility is considered competition capability." }\end{array}$ & (Ho et al., 2016) \\
\hline $\begin{array}{l}\text { Intelligent Information } \\
\text { system }\end{array}$ & $\begin{array}{l}\text { "The latest system with upgraded information capacities like CRM or ERP to } \\
\text { enhance the logistics and supply chain support is considered as intelligent } \\
\text { information system." }\end{array}$ & $\begin{array}{l}\text { (Alzoubi, 2018; Bourekkadi } \\
\text { et al., 2020; Hahn, 2019; } \\
\text { Kondakov \& Kulik, 2019) }\end{array}$ \\
\hline Supply chain Innovation & $\begin{array}{l}\text { "A radical/incremental change within the process, technology or network of a } \\
\text { supply chain, individually or collectively, that happens in the relevant industry, } \\
\text { company or supply chain, and aims to boost the process of stakeholder's value } \\
\text { creation." }\end{array}$ & $\begin{array}{l}\text { (Arlbjørn, de Haas, \& } \\
\text { Munksgaard, 2011) }\end{array}$ \\
\hline
\end{tabular}

\section{Literature review}

The sole motive of this study is to explore the supply chain innovation in retail trading SMEs in different regions of Abu Dhabi by considering supply chain integration, supply chain orientation, and competition capability along with the mediation role of intelligent information systems. The historical evidence documenting the findings between the relationship of these constructs are described under their specific heads below. 


\subsection{Supply chain Integration}

Effective integration is a key factor in achieving supply chain innovation (Hosseini, Azizi, \& Sheikhi, 2012). For example, effective supply chain integration enhanced the level of innovation in the supply chain of an automotive firm (Wong, Wong, \& Boon-itt, 2013). A study by Smith and Rupp (2015) examined two manufacturing firms in Brazil and documented the use of the Six Sigma methodology in their supply chain integration and noted its positive effect on supply chain innovation. Ayoub et al. (2017) considered the role of customer and supplier integration in the supply chain system of SMEs in Jordan and found that integration in these two areas were important contributors to overall supply chain innovation. Similar positive results and strong relationships were confirmed by other studies (Adebanjo et al., 2018; Neutzling, Land, Seuring, \& do Nascimento, 2018; Xian, Sambasivan, \& Abdullah, 2018).

\subsection{Supply chain Orientation}

The domain of supply chain innovation in the context of supply chain orientation was rarely examined at any entity level. However, the exploratory research by Xian et al. (2018) revealed an upstream and strong link between innovative supply chain and supply chain orientation for small scale and medium scale manufacturing entities in different regions of Malaysia. Likewise, Jadhav et al. (2019) confirmed an upstream link with a positive coefficient between supply chain orientation and supply chain innovation.

\subsection{Competition capability}

Exploratory research by Ferrer et al. (2011) showed the importance of competition capability in explaining and enhancing innovation in the supply chain. Similar research by Liao, Hu, and Ding (2017), examined 74 SMEs in Taiwan and revealed a strong, upstream relationship between competition capability and innovation in the supply chain. An exploratory study by Kwak, Seo, and Mason (2018) on SMEs in South Korea, revealed similar results.

\subsection{Intelligent Information System}

An effective and intelligent information system in the form of Customer Relationship Management (CRM) and Enterprise Resource Planning (ERP) is a pre-requisite for innovative supply chain systems in modern manufacturing firms at all scales and sizes (Marinagi, Trivellas, \& Sakas, 2014). Similarly, a study by Singhry (2015) revealed that an innovative supply chain system can be achieved through a continues upgradation of an intelligent information system in the supply chain. Similar evidence of the upstream link and strong positive correlation between an intelligent information system and supply chain innovation was documented by (Hahn, 2019).

\section{Research challenges}

The historical evidence describes the upstream directions and strength of relationships between supply chain integration, supply chain orientation, competition capability, and supply chain innovation in different industrial and trading concerns around the world. The retail trading SMEs in Abu Dhabi were neglected in the past and this may create ambiguity regarding the innovative capacity of these firms in the above-mentioned areas. Also, the upgradation of an intelligent information system may enhance the impact of supply chain integration, supply chain orientation, and competitive capability in achieving innovation in the supply chain of retail trading SMEs in Abu Dhabi.

Considering the above research problems, the study aims to achieve the following objectives regarding retail trading SMEs in Abu Dhabi:

- To confirm the upstream link and importance of supply chain integration in achieving supply chain innovation,

- To verify the direct and significant impact that supply chain orientation has on supply chain innovation,

- To confirm the positive and durable capacity of competitive capability in realizing the innovation in the supply chain,

- To explore the mediation capacity of intelligent information systems in obtaining an innovative supply chain.

\subsection{Research model}

The present study requires the constructs along with their dimension and important items, which are elaborated in Table 2.

The research problem and objectives of this study require the testing of the following research hypotheses:

$\boldsymbol{H}_{\mathbf{1}}$ : Innovation in supply chain of retail trading SMEs in Abu Dhabi can be ensured by improving efficiency of integration in the supply chain.

$\boldsymbol{H}_{2}$ : Supply chain orientation plays a strong role in upstreaming the innovative activities of the supply chain in retail trading SMEs of Abu Dhabi. 
$\boldsymbol{H}_{3}$ : The competitive capability of retail trading SMEs in Abu Dhabi has a strong capacity to enhance the innovative supply chain in their system.

$\boldsymbol{H}_{4}$ : An intelligent information system can strengthen the capacity of supply chain integration, supply chain orientation, and competitive capability and achieve supply chain innovation in retail trading SMEs of Abu Dhabi.

Table 2

Variables and their dimensions

\begin{tabular}{|c|c|c|c|}
\hline Type & Constructs & Dimensions & Items \\
\hline \multirow[t]{5}{*}{ DV } & Supply chain Innovation & SCI & SCI1 \\
\hline & & & $\mathrm{SCI} 2$ \\
\hline & & & SCI3 \\
\hline & & & $\mathrm{SCI} 4$ \\
\hline & & & SCI5 \\
\hline \multirow[t]{6}{*}{ IV1 } & Supply chain integration & Customer Integration & CI1 \\
\hline & & & $\mathrm{CI} 2$ \\
\hline & & & $\mathrm{CI} 3$ \\
\hline & & Supplier Integration & SI1 \\
\hline & & & SI2 \\
\hline & & & $\mathrm{SI} 3$ \\
\hline \multirow[t]{8}{*}{ IV2 } & Supply chain orientation & Attitude & SCOA1 \\
\hline & & & $\mathrm{SCOA} 2$ \\
\hline & & & SCOA3 \\
\hline & & & SCOA4 \\
\hline & & Intentions & SCOI1 \\
\hline & & & SCOI2 \\
\hline & & & SCOI3 \\
\hline & & & SCOI4 \\
\hline \multirow[t]{16}{*}{ IV3 } & Competition capability & Quality & CCQ1 \\
\hline & & & CCQ2 \\
\hline & & & CCQ3 \\
\hline & & & CCQ4 \\
\hline & & Cost & $\mathrm{CCC} 1$ \\
\hline & & & $\mathrm{CCC} 2$ \\
\hline & & & $\mathrm{CCC} 3$ \\
\hline & & & CCC4 \\
\hline & & Delivery & CCD1 \\
\hline & & & $\mathrm{CCD} 2$ \\
\hline & & & CCD3 \\
\hline & & & CCD4 \\
\hline & & Flexibility & CCF1 \\
\hline & & & $\mathrm{CCF} 2$ \\
\hline & & & CCF3 \\
\hline & & & $\mathrm{CCF} 4$ \\
\hline \multirow[t]{5}{*}{ Mediator } & Intelligent Information system & IIS & IIS1 \\
\hline & & & IIS2 \\
\hline & & & IIS3 \\
\hline & & & IIS4 \\
\hline & & & IIS5 \\
\hline
\end{tabular}

The study aims to achieve supply chain innovation in the retail trading SMEs of Abu Dhabi by analyzing the probable impact of supply chain integration, supply chain orientation, and competitive capability as a direct link, while also considering intelligent information systems as the mediator for the present examination of the research. It is an exploratory study based on primary data collection.

\subsection{Populaition and sample}

The study focuses on the retail trading SMEs in Abu Dhabi. The total number of SMEs in Dubai is 3623 (SCAD, 2020). Off these, $73 \%$ are in the retail trade segments. The study employs random sampling to choose approximately 300 retail trading SMEs. The unit of analysis comprises the managerial personnel working in these retail trading SMEs. 


\subsection{Data collection method}

The study uses an exploratory approach based on primary data collection techniques. A two-part online questionnaire format is used. The first part is the demographic section, which contains information on gender, education, position, and experience of the managerial personnel as well as details regarding firm size. The second part contains questions and items related to supply chain innovation, supply chain integration, supply chain orientation, competition capabilities, and intelligent information systems. Around 600 online questionnaires were emailed to managerial personnel working in the sampled SMEs in Abu Dhabi. A total of 473 responses were received, of which 357 were considered accurate for data analysis. The constructs are measured on a five-point Likert scale (choices ranging from strong disagreement (1/5) to strong agreement $(5 / 5))$.

\subsection{Data analysis and discussion}

The data collected is analyzed with primary data analysis techniques using SPSS (for descriptive analysis) and Smart PLS for remaining hypotheses testing. The results of the analysis are presented in Tables 3-6 and Figs. 2-3.

Table 3

Descriptive Statistics of Demographic Factors

\begin{tabular}{|c|c|c|c|c|}
\hline & Mean & SD & Frequency & $(\%)$ \\
\hline Gender & .66 & .474 & 357 & 100 \\
\hline Female & & & 121 & 33.9 \\
\hline Male & & & 236 & 66.1 \\
\hline Education & 2.10 & .791 & 357 & 100 \\
\hline Undergraduate & & & 96 & 26.9 \\
\hline Graduate & & & 131 & 36.7 \\
\hline Postgraduate & & & 130 & 36.4 \\
\hline Position & 2.03 & .945 & 357 & 100 \\
\hline Assistant Manager & & & 130 & 36.4 \\
\hline General Manager & & & 111 & 31.1 \\
\hline Operation Manager & & & 92 & 25.8 \\
\hline Experience & 2.71 & 1.096 & 357 & 100 \\
\hline $0-2$ years & & & 73 & 20.4 \\
\hline $3-5$ years & & & 61 & 17.1 \\
\hline $5-10$ years & & & 119 & 33.3 \\
\hline More than 10 years & & & 104 & 29.1 \\
\hline Firm Size & 1.59 & .492 & 357 & 100 \\
\hline Small & & & 145 & 40.6 \\
\hline Medium & & & 212 & 59.4 \\
\hline
\end{tabular}

Table 3 summarizes the descriptive estimates in percentage, frequency, standard deviation, and mean values for the respondents' demographic features. In sum, $66 \%$ of the respondents were male; the average respondent was either a graduate or a post-graduate; most were assistant managers with experience of 5-10 years; and most firms that participated were medium sized.

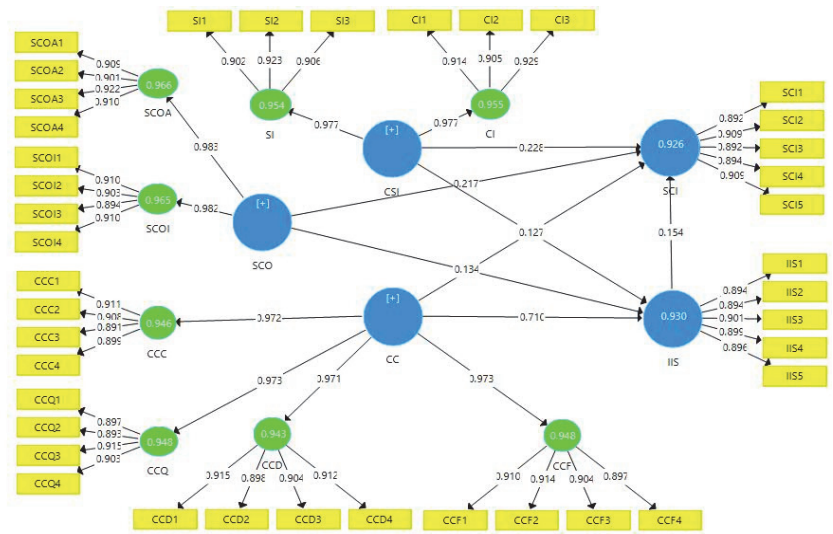

Fig. 2. Factor Model

The above figure (Fig. 2) elaborates the constructs and their factors. It provides the estimation of loading values required to explain the constructs, the path coefficient value for the relationship between constructs, and R-square value for the dependent variable (innovative supply chain) and mediating variable like intelligent information system (IIS). The innovation in the supply chain (SCI) is strongly determined by five items (SCI 1-5). The intelligent information system (IIS) is also significantly measured by five items (IIS 1-5). The R-square value for SCI and IIS is $92.6 \%$ and $93 \%$ respectively. The remaining constructs like supply chain integration (CSI), supply chain orientation (SCO), and competition capability (CC) are determined based on second-order constructs. Table 4 indicates the outer loading values of all the constructs' dimensions and their items, along with the internal reliability and validity. 
Table 4

Outer Loadings and Internal Reliability \& Validity

\begin{tabular}{|c|c|c|c|c|}
\hline Factors & Loadings & Cronbach Alpha & CR & AVE \\
\hline Cost & & \multirow[t]{5}{*}{0.924} & \multirow[t]{5}{*}{0.946} & \multirow[t]{5}{*}{0.814} \\
\hline$C C C 1$ & 0.911 & & & \\
\hline$C C C 2$ & 0.908 & & & \\
\hline$C C C 3$ & 0.891 & & & \\
\hline CCC4 & 0.899 & & & \\
\hline Delivery & & \multirow[t]{5}{*}{0.928} & \multirow[t]{5}{*}{0.949} & \multirow[t]{5}{*}{0.823} \\
\hline$C C D 1$ & 0.915 & & & \\
\hline$C C D 2$ & 0.898 & & & \\
\hline$C C D 3$ & 0.904 & & & \\
\hline CCD4 & 0.912 & & & \\
\hline Flexibility & & \multirow[t]{5}{*}{0.927} & \multirow[t]{5}{*}{0.948} & \multirow[t]{5}{*}{0.821} \\
\hline$C C F 1$ & 0.910 & & & \\
\hline$C C F 2$ & 0.914 & & & \\
\hline$C C F 3$ & 0.904 & & & \\
\hline CCF4 & 0.897 & & & \\
\hline Quality & & \multirow{5}{*}{0.924} & \multirow[t]{5}{*}{0.946} & \multirow[t]{5}{*}{0.814} \\
\hline$C C Q 1$ & 0.897 & & & \\
\hline$C C Q 2$ & 0.893 & & & \\
\hline$C C Q 3$ & 0.915 & & & \\
\hline CCQ4 & 0.903 & & & \\
\hline Customer Integration & & \multirow[t]{4}{*}{0.904} & \multirow{4}{*}{0.940} & \multirow{4}{*}{0.839} \\
\hline CII & 0.914 & & & \\
\hline CI2 & 0.905 & & & \\
\hline CI3 & 0.929 & & & \\
\hline Intelligent Information System & & \multirow{6}{*}{0.939} & \multirow[t]{6}{*}{0.954} & \multirow[t]{6}{*}{0.804} \\
\hline IISI & 0.894 & & & \\
\hline IIS 2 & 0.894 & & & \\
\hline IIS3 & 0.901 & & & \\
\hline IIS4 & 0.899 & & & \\
\hline IIS5 & 0.896 & & & \\
\hline Supply chain Innovation & & \multirow[t]{6}{*}{0.941} & \multirow[t]{6}{*}{0.955} & \multirow[t]{6}{*}{0.809} \\
\hline SCII & 0.892 & & & \\
\hline SCI2 & 0.909 & & & \\
\hline$S C I 3$ & 0.892 & & & \\
\hline SCI4 & 0.894 & & & \\
\hline SCI5 & 0.909 & & & \\
\hline Attitude & & 0.931 & 0.951 & 0.829 \\
\hline SCOA1 & 0.909 & & & \\
\hline SCOA2 & 0.901 & & & \\
\hline SCOA3 & 0.922 & & & \\
\hline SCOA4 & 0.910 & & & \\
\hline Intentions & & 0.926 & 0.947 & 0.818 \\
\hline SCOII & 0.910 & & & \\
\hline SCOI2 & 0.903 & & & \\
\hline SCOI3 & 0.894 & & & \\
\hline SCOI4 & 0.910 & & & \\
\hline Supplier Integration & & 0.897 & 0.936 & 0.829 \\
\hline SII & 0.902 & & & \\
\hline$S I 2$ & 0.923 & & & \\
\hline$S I 3$ & 0.906 & & & \\
\hline
\end{tabular}

The minimum acceptable level for factor loading is 0.70 , for Cronbach's alpha and CR is 0.70 and for average variance extracted (AVE) is 0.50. According to the estimated values reported in Table 4, all the constructs, their dimensions, and relevant items are valid and internally reliable. Table 5 shows the discriminant validity measuring the external reliability and validity of constructs based on Fornell-Larcker criterion. According to the criterion, all the constructs are externally valid and reliable for this examination of research.

Table 5

Discriminant Validity (Fornell-Larcker Criterion)

\begin{tabular}{|c|c|c|c|c|c|c|c|c|c|c|c|c|c|}
\hline & $\mathrm{CC}$ & $\mathrm{CCC}$ & CCD & $\mathrm{CCF}$ & CCQ & CI & CSI & IIS & SCI & SCO & SCOA & SCOI & SI \\
\hline $\mathrm{CC}$ & 0.880 & & & & & & & & & & & & \\
\hline $\mathrm{CCC}$ & 0.972 & 0.902 & & & & & & & & & & & \\
\hline CCD & 0.971 & 0.924 & 0.907 & & & & & & & & & & \\
\hline $\mathrm{CCF}$ & 0.973 & 0.926 & 0.930 & 0.906 & & & & & & & & & \\
\hline CCQ & 0.973 & 0.933 & 0.923 & 0.931 & 0.902 & & & & & & & & \\
\hline CI & 0.941 & 0.918 & 0.913 & 0.912 & 0.917 & 0.916 & & & & & & & \\
\hline CSI & 0.966 & 0.946 & 0.940 & 0.936 & 0.935 & 0.977 & 0.892 & & & & & & \\
\hline IIS & 0.963 & 0.936 & 0.933 & 0.941 & 0.936 & 0.919 & 0.941 & 0.897 & & & & & \\
\hline SCI & 0.957 & 0.928 & 0.933 & 0.929 & 0.932 & 0.923 & 0.945 & 0.937 & 0.899 & & & & \\
\hline SCO & 0.973 & 0.949 & 0.946 & 0.943 & 0.945 & 0.934 & 0.959 & 0.946 & 0.948 & 0.892 & & & \\
\hline SCOA & 0.960 & 0.934 & 0.935 & 0.933 & 0.933 & 0.924 & 0.945 & 0.934 & 0.933 & 0.983 & 0.911 & & \\
\hline SCOI & 0.951 & 0.932 & 0.925 & 0.920 & 0.924 & 0.912 & 0.940 & 0.925 & 0.930 & 0.982 & 0.931 & 0.904 & \\
\hline SI & 0.946 & 0.930 & 0.923 & 0.916 & 0.910 & 0.909 & 0.977 & 0.920 & 0.924 & 0.940 & 0.921 & 0.926 & 0.910 \\
\hline
\end{tabular}




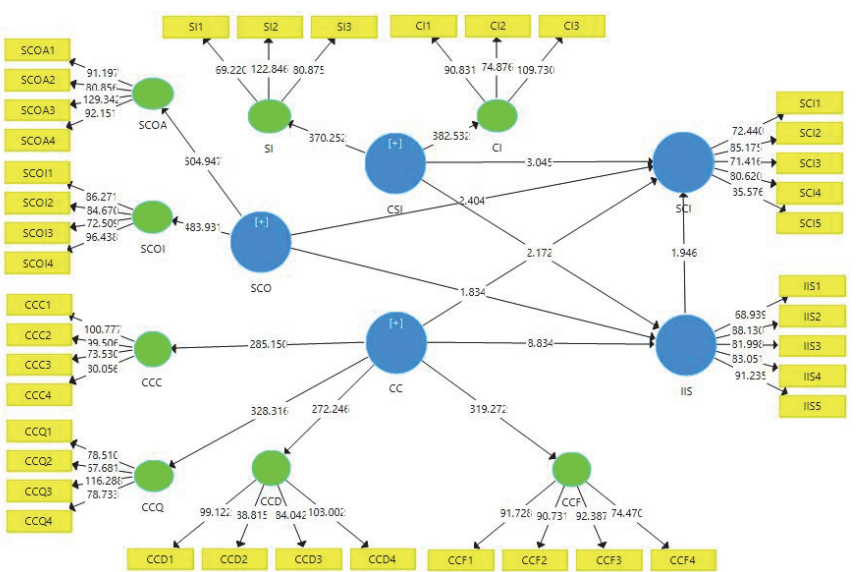

Fig. 3. Structural Equation Model

The above figure (Fig. 3) elaborates the structural equation model. The figure indicates the relational significance between the constructs. For a significant link between the constructs, the t-value must be greater than 1.96. The figure indicates that the relational path between supply chain orientation and an intelligent information system is not significant. Similarly, the relationship between intelligent information system and innovative supply chain is also not significant as the t-value is less than 1.96. In the remaining relational paths, the t-value is greater than 1.96 and thus they are significant.

Table 6

SEM Estimations

\begin{tabular}{|c|c|c|c|c|c|}
\hline Total Effect & (O) & (M) & (STDEV) & T Statistics & P Values \\
\hline$C C \rightarrow C C C$ & 0.972 & 0.973 & 0.003 & 285.150 & 0.000 \\
\hline$C C \rightarrow C C D$ & 0.971 & 0.971 & 0.004 & 272.246 & 0.000 \\
\hline$C C \rightarrow C C F$ & 0.973 & 0.974 & 0.003 & 319.272 & 0.000 \\
\hline$C C \rightarrow C C Q$ & 0.973 & 0.973 & 0.003 & 328.316 & 0.000 \\
\hline$C C \rightarrow I I S$ & 0.710 & 0.701 & 0.080 & 8.834 & 0.000 \\
\hline$C C \rightarrow S C I$ & 0.486 & 0.478 & 0.098 & 4.940 & 0.000 \\
\hline$C S I \rightarrow C I$ & 0.977 & 0.977 & 0.003 & 382.532 & 0.000 \\
\hline$C S I \rightarrow I I S$ & 0.127 & 0.130 & 0.059 & 2.172 & 0.030 \\
\hline$C S I \rightarrow S C I$ & 0.248 & 0.254 & 0.074 & 3.347 & 0.001 \\
\hline$C S I \rightarrow S I$ & 0.977 & 0.977 & 0.003 & 370.252 & 0.000 \\
\hline$I I S \rightarrow S C I$ & 0.154 & 0.156 & 0.079 & 1.946 & 0.052 \\
\hline$S C O \rightarrow I I S$ & 0.134 & 0.140 & 0.073 & 1.834 & 0.067 \\
\hline$S C O \rightarrow S C I$ & 0.238 & 0.240 & 0.090 & 2.633 & 0.009 \\
\hline$S C O \rightarrow S C O A$ & 0.983 & 0.983 & 0.002 & 504.947 & 0.000 \\
\hline$S C O \rightarrow S C O I$ & 0.982 & 0.982 & 0.002 & 483.931 & 0.000 \\
\hline \multicolumn{6}{|c|}{ Specific Indirect Effect } \\
\hline$C C \rightarrow I I S \rightarrow S C I$ & 0.109 & 0.109 & 0.056 & 1.955 & 0.051 \\
\hline$C S I \rightarrow I I S \rightarrow S C I$ & 0.020 & 0.021 & 0.016 & 1.235 & 0.217 \\
\hline$S C O \rightarrow I I S \rightarrow S C I$ & 0.021 & 0.021 & 0.016 & 1.278 & 0.202 \\
\hline \multicolumn{6}{|l|}{ R-square } \\
\hline IIS & 0.930 & 0.931 & 0.008 & 120.379 & 0.000 \\
\hline$S C I$ & 0.926 & 0.928 & 0.010 & 92.844 & 0.000 \\
\hline \multicolumn{6}{|l|}{ Adj-R-square } \\
\hline IIS & 0.929 & 0.930 & 0.008 & 119.288 & 0.000 \\
\hline$S C I$ & 0.925 & 0.927 & 0.010 & 91.718 & 0.000 \\
\hline
\end{tabular}

Table 6 elaborates the total and specific effects of constructs as per the relational paths described in Fig. 2 and Fig. 3 . The "total effect" segment of the table shows that all the constructs like supply chain integration, supply chain orientation, and competition capability are key contributors to supply chain innovation in retail trading SMEs of Abu Dhabi. In the case of supply chain orientation towards intelligent information systems and intelligent information systems towards supply chain innovation, the impact is less significant. The "specific indirect effect" segment of the above table (Table 6), shows that the link between intelligent information systems and competition capability of retail trading SMEs of Dubai is weak, with a significance of just 5\%. Intelligent information systems do not strongly mediate the relationship between supply chain integration, supply chain orientation, and innovative supply chain.

\section{Conclusion and recommendations}

The aim of this study was to investigate the supply chain innovation in retail trading SMEs in different regions of Abu Dhabi by considering the mediation role that intelligent information systems has on supply chain integration, supply chain orientation, and competition capability. The study has used primary data exploratory technique for data collection, along with the help of online questionnaires emailed to 600 managerial employees working in retail trade SMEs of Abu Dhabi. A total of 357 completed responses were used in the analysis of this study. All the constructs were internally and externally estimated to be reliable and valid, based on factor loading values, Cronbach's alpha, composite reliability, AVE, and 
discriminant validity. The "total effect" segment of the table elaborates constructs like supply chain integration, supply chain orientation, and competition capability are key contributors to supply chain innovation in retail trading SMEs of Abu Dhabi. In the case of supply chain orientation towards intelligent information systems and intelligent information systems towards supply chain innovation, the impact is less significant. The "specific indirect effect" segment of Table 6 shows that the link between intelligent information systems and competition capability of retail trading SMEs of Dubai is weak, with a significance of just $5 \%$. Intelligent information systems do not strongly mediate the relationship between supply chain integration, supply chain orientation, and supply chain innovation. The management and policymakers of retail trade SMEs in Abu Dhabi are advised to consider strongly, the role of supply chain integration, supply chain orientation, and competition capability in achieving supply chain innovation. The outcomes of this exploratory study apply only to the retail sector of SMEs in Abu Dhabi, which is the capital of United Arab Emirates.

\section{References}

Aboelmaged, M. (2018). The drivers of sustainable manufacturing practices in Egyptian SMEs and their impact on competitive capabilities: A PLS-SEM model. Journal of Cleaner Production, 175, 207-221.

Adebanjo, D., Teh, P.-L., \& Ahmed, P. K. (2017). The impact of supply chain relationships and integration on innovative capabilities and manufacturing performance: the perspective of rapidly developing countries. International Journal of Production Research, 56(4), 1708-1721.

Alzoubi, H. (2018). The role of intelligent information system in e-supply chain management performance. International Journal of Multidisciplinary Thought, 7(2), 363-370.

Arlbjørn, J. S., de Haas, H., \& Munksgaard, K. B. (2011). Exploring supply chain innovation. Logistics research, 3(1), 3-18.

Ayoub, H. F., Abdallah, A. B., \& Suifan, T. S. (2017). The effect of supply chain integration on technical innovation in Jordan. Benchmarking: An International Journal, 24(3), 594-616.

Bourekkadi, S., Slimani, K., Babounia, A., Moumen, A., Hannaoui, M., Fakhri, Y., \& Khoulji, S. (2020). Modeling of an Intelligent Information System Serving the Environment: Water Resources. Paper presented at the Proceedings of the 4th Edition of International Conference on Geo-IT and Water Resources 2020, Geo-IT and Water Resources 2020, ACM, Al Hoceima, Maroc.

Ferrer, M., Santa, R., Storer, M., \& Hyland, P. (2011). Competences and capabilities for innovation in supply chain relationships. International Journal of Technology Management, 56(2/3/4), 272-289.

Hahn, G. J. (2019). Industry 4.0: a supply chain innovation perspective. International Journal of Production Research, 58(5), 1425-1441.

Ho, T. C., Ahmad, N. H., \& Ramayah, T. (2016). Competitive capabilities and business performance among manufacturing SMEs: Evidence from an emerging economy, Malaysia. Journal of Asia-Pacific Business, 17(1), 37-58.

Jadhav, A., Orr, S., \& Malik, M. (2019). The role of supply chain orientation in achieving supply chain sustainability. International Journal of Production Economics, 217, 112-125.

Kondakov, A., \& Kulik, S. (2020). Intelligent Information System for Telemedicine. Procedia Computer Science, 169, $240-243$.

Kwak, D.-W., Seo, Y.-J., \& Mason, R. (2018). Investigating the relationship between supply chain innovation, risk management capabilities and competitive advantage in global supply chains. International Journal of Operations \& Production Management, $38(1), 2-21$.

Liao, S. H., Hu, D. C., \& Ding, L. W. (2017). Assessing the influence of supply chain collaboration value innovation, supply chain capability and competitive advantage in Taiwan's networking communication industry. International Journal of Production Economics, 191, 143-153.

Mahmood Hosseini, S. M., Azizi, S., \& Sheikhi, N. (2012). An investigation on the effect of supply chain integration on competitive capability: an empirical analysis of Iranian food industry. International Journal of Business and Management, 7(5), 73-90.

Mandal, S., \& Scholar, V. (2011). Supply Chain Innovation: A dynamic Capability Perspective. American Council of Supply Chain Management Professionals, 1-10.

Marinagi, C., Trivellas, P., \& Sakas, D. P. (2014). The impact of information technology on the development of supply chain competitive advantage. Procedia-Social and Behavioral Sciences, 147, 586-591.

Neutzling, D. M., Land, A., Seuring, S., \& Nascimento, L. F. M. do. (2018). Linking sustainability-oriented innovation to supply chain relationship integration. Journal of Cleaner Production, 172, 3448-3458.

Rahim Sid Ahmed, M. A., \& Wiegert, R. (2019). Small and Medium-sized Enterprises in Abu Dhabi. Abu Dhabi Chamber: Abu Dhabi Chamber.

SCAD. (2020). Economic Survey Result Wholesale and Retail Trade. Abu Dhabi: Statistics Center.

Schulze-Ehlers, B., Steffen, N., Busch, G., \& Spiller, A. (2014). Supply chain orientation in SMEs as an attitudinal construct. Supply Chain Management: An International Journal, 19(4), 395-412.

Singhry, H. B. (2015). Effect of supply chain technology, supply chain collaboration and innovation capability on supply chain performance of manufacturing companies. Journal of Business Studies Quarterly, 7(2), 258-273.

Smith, A. D., \& Rupp, W. T. (2015). Supply chain integration and innovation in a global environment: case studies of best business practices. International Journal of Logistics Systems and Management, 22(3), 313-330.

Wong, C. W. Y, Wong, C. Y., \& Boon-itt, S. (2013). The combined effects of internal and external supply chain integration on product innovation. International Journal of Production Economics, 146(2), 566-574.

Xian, K. J., Sambasivan, M., \& Abdullah, A. R. (2018). Impact of market orientation, learning orientation, and supply chain integration on product innovation. International Journal of Integrated Supply Management, 12(1/2), 69-89.

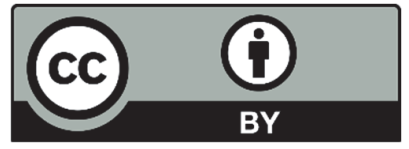

(C) 2020 by the authors; licensee Growing Science, Canada. This is an open access article distributed under the terms and conditions of the Creative Commons Attribution (CC-BY) license (http://creativecommons.org/licenses/by/4.0/). 